\title{
Virtuous Learning Environments: The VLE and the Library
}

\author{
John MacColl, \\ Director of SELLIC (Science \& Engineering Library, \\ Learning \& Information Centre)/ \\ Sub-Librarian, Online Services \\ University of Edinburgh \\ Darwin Library \\ The King's Buildings \\ Mayfield Road \\ Edinburgh EH9 3JU \\ john.maccoll@ed.ac.uk
}

\section{Abstract}

This paper describes the growing use of virtual learning environments in learning and teaching in UK HE. The distinction between content management and its presentation by web delivery systems is discussed. The way in which academic libraries should be involved in the development of these environments is identified with reference to Project ANGEL - a new project funded by the Joint Information Systems Committee in the UK. Overlap between virtual learning environments and electronic reserve systems in libraries is discussed in the context of the requirement that academic libraries assert their role as resource information managers in their institutions. Discharging this function will require genuine partnership between academic librarians and course tutors, and a fuller integration of the Library into the course creation and delivery processes.

\section{Virtual Learning Environments}

'Virtual' or 'Managed' Learning Environments (VLEs or MLEs) have been in use in UK higher education for several years. Some institutions have embraced them wholeheartedly, setting up VLEs for all courses in the curriculum. Most, however, have moved gradually to making more use of them, with early adopters in particular Faculties leading the way. Some have purchased site licences for a particular VLE product which is then promoted and supported by learning technology or IT services. Others have allowed a variety of products to be tested, waiting to see whether a market leader emerges, or whether different VLEs are better suited to different disciplines. Still others have developed their own products.

For the student, an online learning environment is a convenient way of accessing a range of material connected with a course of study. Since the vast majority of all of the asynchronous components of a typical course of study - the study materials, the administrative information and the exchanges between academic staff and students - are today 'born digital', a VLE offers no more than a logical modular structure into which these components can be fitted. In their report for JISC's Technology Applications Programme, A Framework for Pedagogical Evaluation of Virtual Learning Environments, Oleg Liber and Sandy Britain of the UK IMS Centre describe VLEs as 'learning management software systems that synthesise the functionality of computer-mediated communications software (e-mail, bulletin boards, newsgroups etc) and on-line methods of delivering course materials'.

VLEs began to come to attention in the second half of the 1990s. They were initially nonweb-based - and some still are. Learning Landscapes, for example, developed by Bangor on behalf of JISC, depended entirely on client software when it was released in 1998 (it is now known as Colloquia, ${ }^{1}$ and is slowly moving to a web platform). Gradually, however, the web has taken over as the dominant form, for obvious reasons. As lecturers adopt VLEs, the support staff in computing services have less trouble in providing networked personal computers with web browsers than they do in providing the same computers with specialised client software. The main advantage in developing courses on the web, however, is the ability 
to link resources in from elsewhere on the intranet or internet. The leading VLE in HE at the present time is probably WebCT ${ }^{2}$. Other significant players are CourseInfo from Blackboard ${ }^{3}$ and TopClass. ${ }^{4}$ A number of universities have also produced environments for use in their own institutions, and for licensing to others. Examples are Merlin at the University of Hull ${ }^{5}$ and COSE at Staffordshire University, ${ }^{6}$ which is now marketed by Cambridge Software Publishing.

In general, these applications offer a common range of functions, which comprise the following basic set:

- Email to allow broadcasting of messages to the course group, and individual dialogue between students and tutors

- Alerting

- Calendar/scheduling, to accommodate timetabling information

- A structure to facilitate course and module description

- A facility to permit other web resources to be linked in

- Assessment tools (typically shells which permit multiple choice tests to be developed).

The diagram below shows the modules commonly found in VLE systems:

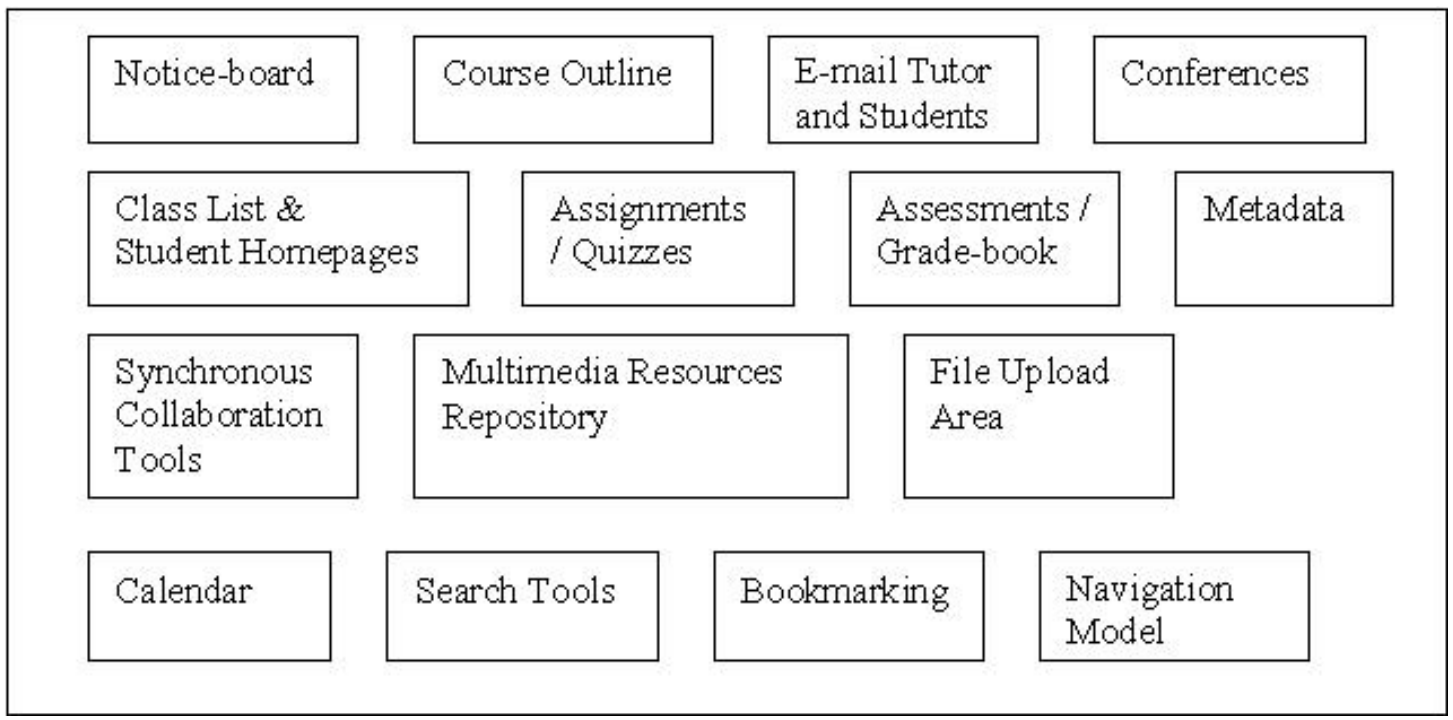

Schematic diagram of a 'prototypical VLE' (source: Britain, S. and Liber, O. 'A Framework for Pedagogical Evaluation of Virtual Learning Environments'. JISC Technology Applications Programme report)

\section{Content Management}

The availability of a VLE does not of course mean that courses can be simply 'transferred' online. Ultimately, content is what matters, and while VLEs assist tutors in structuring content, they do not generate it of themselves.

Robin Mason of the Open University classified VLEs into three types in an article published in $1998^{7}$

1. 'Content + support.' This was the earliest model of online education, and is still the most prevalent. The core course materials are relatively static, and will usually be 
printed, although web resources are now more common. The online element provides for rudimentary interactivity with tutors by email or computer conferencing, but this often appears to be 'bolted on' to a core of content which has to be learned. Students typically will spend no more than about $20 \%$ of their total course work time online, and often complain of a lack of integration between the static online course material and the surrounding activity of the course. This is the model which has been dominant within the teaching methods of the Open University since its inception. Its primary rationale is cost, since it delivers economies of scale - which are of course essential to the ability of the OU to carry out its form of education.

2. 'Wrap around.' In this model, the breakdown between course material and activity is closer to 50/50. The online element provides the medium for discussion and interaction around a core of resource material which, again, is usually printed. This model is more resource-based, giving students scope to develop by themselves, and providing the tutor with more opportunity for creativity in the online space. It makes the course less static, as it changes and grows with each delivery.

3. 'Integrated model.' This model is at the opposite end of the spectrum from the 'content + support' model. It uses the online medium more flexibly, using collaborative activities, joint assignments and resource materials in a highly interlinked way. Mason presents this as the most dynamic model:

'In a sense, the integrated model dissolves the distinction between content and support, and is dependent on the creation of a learning community.'

This model is pioneering, and breaks down some of the established teaching and learning paradigms. One way, for example, is by allowing students to conduct peer assessment of each other's work. Mason states 'Just as the Web turns everyone into a publisher, so online courses give everyone the opportunity to be the teacher.'

Mason goes on to state that, as distinct from its early days when the predominant model was that of 'content + support,' VLEs are now responsible for changing the way learning and teaching happen:

'I would contend that online courses are driving pedagogical evolution in higher education generally, because of the rush to digitize, virtualize and globalize the campus.'

With the integrated model, which is the one towards which the learning environments currently in use in our universities are likely to evolve, learners and teachers become jointly responsible for the resources of a course. This positive development in pedagogy threatens another paradigm, however, which is the Library's role in resource management on behalf of the institution. As librarians, we cannot be unaware of the constant use of the term 'resources' in the description of these products. But the Library considers itself to be the institution's learning resource manager - at least in respect of shared resources. How do we librarians know which resources are being added? If we don't know, we cannot make decisions on which resources to select for description in the Library's systems - which we are currently extending to accommodate web and online resources. Even if we do know, how do we judge between the contending claims of a newly-linked web site, added in to the learning environment by a student, a growing discussion archive on a local server, a coursebook produced by a lecturer, and online ejournal articles and reports which the lecturer wishes to include among their course resources?

Outwith the academic sphere, 'content management systems' have been appearing recently. These aim to separate the presentation of content from its creation and management, allowing web sites to be constructed collaboratively by authors who need not be aware of the 
intricacies of web site creation and maintenance - HTML tagging, scripting languages, style sheets, server-side includes and the other techniques required by web site editors. A new content management system for higher education is currently under development by a company based in Edinburgh. ${ }^{8}$ The author need only interface with the content management system, adding and editing files. The system will take care of the conversion of content for whatever presentational system is in use, and will use a markup language (typically XML, the Extensible Markup Language) in order to 'future-proof' the content so that it can be delivered through different presentational systems. It will also ensure compliance with the emerging raft of international standards for educational courseware, in particular those under development by the Instructional Management Systems (IMS) Project, ${ }^{9}$ and SCORM, the Shareable Courseware Object Reference Model ${ }^{10}$ which are being defined by government bodies and many of the large commercial vendors in this field. This combination of high-level markup and adherence to interoperability through standards should ensure that digital objects managed by a content management system are preserved for future use and re-use. In the academic world, this will 'protect' the content in the event that a university or department chooses to switch to a new VLE.

\section{Project ANGEL}

Under its programme for the Development of the DNER (Distributed National Electronic Resource), the Joint Information Systems Committee (JISC) had funded a consortium project known as ANGEL (Authenticated Networked Guided Environment for Learning), which is led by the London School of Economics, with partners at the University of Edinburgh, De Montfort University, South Bank University and associate partners EDINA (Edinburgh Data and Information Access) and Sheffield Hallam University.

ANGEL will develop an environment for learning which will be 'guided' in several ways. Users will be guided in the sense of entering a tailored, customised environment - an individual portal which collocates administrative and academic information which relates to them - from registry, library, finance, faculty and department. Such an approach is no longer a new one. Individual universities (such as the University of Sydney, with MyUni ${ }^{11}$ ) have developed personalisable student environments. 'Off the peg' portal creation systems such as Campus Pipeline, ${ }^{12}$ also exist. What ANGEL hopes to offer, however, is 'deep guidance' through the development of middleware which will be the most important component of the system. The software 'angel' which comes to the assistance of students will not insist on any particular interface (thus it will work with existing customised or institutionally-preferred portals), though it will provide one for institutions which wish. What it will do, however, is store a dynamic user profile in order to present the user's environment as one which is familiar.

At the heart of the ANGEL system is the tutor interface, which is the way by which the 'guiding' of the student user is achieved. ANGEL will build tools to make it simple for tutors, as they construct online courses, to select resources which should be added to the environments of all students on their course. They will be prompted to select from a range of resources both local and external, including DNER resources such as the databases and datasets available from the data centres as well as useful learning resources at various levels from the aggregated level of the online course itself (and other online courses which may be relevant), to the specific level of the course document.

Users will then be guided, through sophisticated authentication developments based on the developing Sparta protocol, to an environment in which all networked resources to which they have rights are available via a 'single sign-on'. In other words, they will not face multiple ID and password challenges as they take their search from resource to resource. Resources to which they do not have rights (perhaps because they are students on a franchised course, for example, or lifelong learners, and resource providers do not recognise them within site licence 
provisions) will not be visible to them.

Mason's claim that the availability of a new way of doing things - teaching using the web - is changing the pedagogical paradigm in HE, is paralleled also in the way the packaging of course material from various components is achieved, and for the ANGEL tutor interface to work effectively implies a high level of collaboration between course organisers and library staff. For, if an academic is to be responsible for selecting the learning resources of their students on a particular course, then it is obvious that they should consult with, or preferably work collaboratively with, a librarian. This implies that library staff should be involved in course teams - a practice which is not unknown, but is certainly far from widespread in UK universities, particularly the older, research-oriented universities.

ANGEL is addressing the requirement stated by Professor John Slater in the recent proceedings of the Workshop on JISC's Final Report on Managed Learning Environments: ${ }^{13}$ He describes the need for administrative and academic information to fit together in a managed learning environment:

'In turn the progression system needs to be linked to the Virtual Learning Environment, which itself can be linked to national resources and initiatives such as the DNER, an initiative bringing together electronic datasets and materials in a coherent way to provide support for learning and teaching activities. Local and regional resources and materials can be added to the overall environment.'

The reference to the DNER is very encouraging for librarians, but who should take responsibility for harvesting DNER resources? The consensus which emerged from this workshop is that a team is required, and the library must be included.

\section{Electronic Reserves and the VLE}

Nevertheless, there is still a lack of appreciation of how deeply the library should be involved. The workshop speaks of library integration as being chiefly at the level of providing access to students to their circulation records, or allowing them to reserve books. These are very useful features, but they do not go far enough. Now that our web-based library systems are developing electronic reserve systems, there is a burgeoning area of overlap between the 'learning resources' which academics wish to install in their VLEs, and the digitised learning resources which libraries are making available. Both see themselves as developing for the digital age practices which they have always employed in the print age. Libraries are digitising heavily-used book chapters and journal articles, clearing copyright as required, and managing these resources through metadata lodged in electronic reserve systems, which may be modules of their main library management systems. The extent to which we are proceeding by analogy with our traditional practices is highlighted by the word 'reserve' to describe this service. These resources are now no longer reserved in any way: indeed, quite the opposite. Birmingham University Library has recognised this, and calls its service 'key texts', which is much more accurate.

Academics, meanwhile, are providing digital copies of heavily-used book chapters and journal articles via the web to mimic what they did in classrooms by handing round printed copies, or by asking the Library to photocopy specific materials for depositing in the (real) reserve collection. What is being forgotten, or ignored, is the fact that libraries were often involved in the process: certainly in order to manage the reserve collection, but sometimes also in the copyright clearance required under the CLA blanket licence for multiple copying for teaching use. As library staff involved in electronic reserve collection maintenance are only too aware, the requirement to clear copyright has not disappeared in the digital age, but has rather become even more complex. Interestingly, users of Blackboard can now access a service from the Blackboard web site called the 'Academic Resource Center', where they can 
simply pick up free content for adding in to their courses. Copyright is not even mentioned. This appears to be a rather worrying example of the tail wagging the dog. The selection of resources must be the preserve of the tutors, preferably supported by library staff. The idea that a VLE supplier can provide 'off the shelf' content raises questions about whether courses are being packaged from available material, rather than from necessary material. Ideally, the necessary should also be available, and the UK's Higher Education Resources on the Net $(\text { HERON })^{14}$ service, which acts as an agent for university courses requiring to clear copyright and digitise learning materials, is a much safer option.

Ros Pan of Durham University Library described in a recent conference paper ${ }^{15}$ the evolution of e-reserves at Durham, and wondered whether the system was sustainable into the longer term, particularly because, since they had discovered VLEs, academic staff were now frequently choosing to put their own resources into the courses they had begun to build for themselves. If Durham's experience is typical, then libraries have a hard battle to fight, because - even where copyright is cleared - the use of the VLE as the sole manager of the resource is the equivalent of the collection of offprints in the tutor's office. They can be used by the students on one particular course only, and other students on other courses receive no benefit. From an information management viewpoint this is clearly inefficient, and it is particularly ironic that it should be happening on account of the 'liberation' in publishing and distribution wrought by the existence of the web, when the existence of an object in digital form allows multiple simultaneous use, assuming licensing permits. On top of that, of course, is the fact that the Library's bibliographic management systems are ideally suited to description and classification of the resource - and not to use them is to incur further inefficiency.

What is required is for the tutors who build the courses using VLEs or MLEs to work with the Library in adding resources to the Library's e-reserve system, linked back in to the virtual learning environment. We are talking about building fairly simple tools here - the equivalent of serving hatches in walls - which allow communication between academics and their support staff in our libraries. A tool which allows an academic to send a note of required articles and book chapters to librarians, and the latter to respond with the URLs from the ereserve system of the items once cleared, digitised and described, should be simple to build. Less simple is the effective liaison required to sustain the use of the tool. Librarians must secure this liaison by making the process as simple as possible to their academic colleagues, and proving to them that its use is in their interest.

\section{Reclaiming a Role for the Library}

A recent concept to have emerged into our professional terminology is 'middleware'. Middleware is the important software which works 'invisibly' behind the scenes in order to allow client programs, which are where the user starts, to perform complex functions across networks, enabling computers at either end of the interaction to negotiate with each other. Thus, middleware is, for libraries, largely about authentication and authorisation. If I sit down at a PC in my university's library, click on the icon to run Web of Science or Scifinder Scholar, and am quickly connected, I have middleware to thank for making the connection. Middleware has a considerable way to go before it produces such seamless negotiations routinely. More often, the user's experience would be one of having to enter ID and password key combinations before the connection could be made - and that combination may be one of several users may have to carry in their heads. But work is going on into middleware development. Indeed, it is central also to the ANGEL project, which is working with JISC's Committee on Authentication and Security as it steers the development of Sparta, a new access management system for the UK.

In the digital information order, libraries have a role to play as middleware themselves. This, though we never called it such, was our function in the print information order. Scholars and 
students wished to have access to the printed content which represented knowledge. The way to do that in a financially limited institution was to buy the content in a way which could be shared, and the most cost-efficient way to do that was to employ an agent which could purchase and organise the information for retrieval.

Our institutions have not so far acknowledged that they need the same agent in the digital information order, except in the case of electronic journals, which libraries have continued to manage mainly for historical reasons, and also because their distribution has followed the same cost model as their printed forebears. We should be concerned about this. If we look closely at our campuses today, we find academic staff connecting to information without the involvement of the Library, in ways which may satisfy their immediate requirements, but which are not in the best interests of the institution. Virtual learning environments - whether created with off-the-shelf packages, or 'home-made' - are filling with links to relevant web sites and documents. Tutors are digitising articles and book chapters which they can link in to these virtual learning environments. And as content grows, it is being organised by its creators and manipulators using PC and web databases to provide indexes.

Some may consider these developments inevitable, even beneficial. But they are unlikely to be efficient, because information management is being done by people who are paid to teach, to research or to administer teaching and research, rather than by the people paid to manage information. What is more, material is being provided via virtual learning environments to small segments of the student population rather than to the whole. The virtual learning environment which is structured around a course or module is inevitably a selfish learning environment. But properly managed scholarly information is visible from all corners of the institution (and, indeed, the discipline). It is multiply retrievable and interoperable. Only by applying the tools of academic librarianship - the resource description and subject classification, and filing of this information in a single system - can the potential of these digital resources be properly released, in a 'virtuous learning environment.'

This neglect of the value of the library to manage the digital information resources of our universities is not malicious on the part of academics. By and large they as yet do not see any reason why the library should be involved. If they do, but refuse to contact us, it is at least partly likely to be due to a perception that to involve the library will introduce delay and bureaucracy. One of the problems of being managers of printed resources, particularly for large research university libraries, was that the physical shape and substance of our collections did take a lot of effort to acquire, describe and disseminate. We had orders to place with booksellers and record suppliers, backlogs to manage, labels to apply, complex bibliographic description and subject analysis to perform, and barcoded proxies for lending with to create. Academics expected to have to wait for the item they ordered to appear on the library shelves, or in their office for review, and were prepared to tolerate - at least in the case of researchers - the greatest anathema for knowledge workers - the inability to consult new and relevant knowledge as soon as its existence is known. They expected this because it was the price they paid for having the library act as their purchasing proxy.

If we are to be persuasive in the world of digital information in which we now present our services as 'hybrid libraries', we have to do two new things. First, we have to be much quicker. In the case of resources which are not 'toll-gated' (to use Stevan Harnad's expression) ${ }^{16}$ that is not a problem. The academic can have the access now, and we can catch up with the description and collocation later. This is why the cataloguing of 'toll-gated' electronic information - ejournals and ebooks - should now be the highest priority for our cataloguing departments (or metadata units).

Second, we have to create procedures by which we can 'routinise' the selection of electronic resources for our OPACs and subject web pages. In a recent issue of Program, Peter Burnett and Christina Seuring discuss the way a number of US universities have approached the task 
of selection of e-resources, which has commonly been added to the remit of subject librarians or bibliographers. ${ }^{17}$ Typically, the selection decisions are being made using web forms, which relay the information on the resource to the cataloguing department. The authors point out that selection of electronic resources can be complex:

\begin{abstract}
'the ability to choose between different formats that information may be available in as one of the primary problems, also ... the ability to identify what is available, understand legal concerns, interpret service implications and consider preservation ... selectors would probably also have to find out to what degree, if any, they can rely on the various kinds of awards and badges given to websites.'
\end{abstract}

They go on to make an important observation about the ongoing responsibility upon selectors.

'The work of the selectors, however, will not end at submitting their choices to another department. Online resources are subject to change in scope and content, growth, or degradation, therefore the selectors will have to monitor changes in resources they have chosen to ensure that they continue to be up to standard.'

Stock review takes on a somewhat different aspect when the 'stock' consists of web resources - or at least those resources which are dynamic. Librarians need new tools to assist them with such procedures. The CORC (Cooperative Online Resource Program) project of the Online Computer Library Center (OCLC) ${ }^{18}$ is developing a content analysis algorithm which will be able to alert cataloguers to degrees of change in web sites they have catalogued, thus allowing cataloguers the chance to review and perhaps change the description of a site (or deselect it altogether, if quality has dropped).

\title{
The 'Demand Driver'
}

The use of subject library staff as selectors, however, may not sit as comfortably with UK university library practice as it does in the US, where 'subject bibliographers' have traditionally played a much larger role in collection development than have subject librarians in the UK. If we are to adapt and update existing practices for the world of the web, we have to acknowledge that the printed resource management system was largely demand-driven. Academics told libraries, by means of book suggestion forms, which resources they wished to have purchased. Librarians selected 'in the gaps.' How can we introduce a demand-driven way of identifying electronic resources to our metadata editors?

There are two ways, both of which are currently being explored by SELLIC and Library staff at the University of Edinburgh, in conjunction with colleagues in Computing Services. One is to develop a routine for a web crawler program, instructing it to report newly linked sites and newly added objects within the University's total web domain. This will generate a report which can be fed to cataloguers directly - or more appropriately to selectors to weed and then send on to cataloguers. This approach has the advantage of not requiring any additional work of academic staff, but the disadvantage of the likelihood of significant quantities of lowquality resources being identified, which then have to be discarded at selection.

The second approach requires that academic staff send a cataloguer a request for an item to be added when they have the item open in a browser window, despatching a request to be queued in a metadata editor's workfile for a record of a particular resource at a particular URL to be created. This requires a trigger, probably a browser button, to be developed to make the process as simple as possible. This approach has a precedent for CORC cataloguers, who are able to launch the CORC metadata template from their browser by means of a button, and we are working to create the same feature which will then be rolled out to academic staff. Naturally, this is harder work in the first instance, since it requires that the Library is able to motivate academic staff not only to fetch the browser button and install it, but also to remember to use it on a regular basis. This work of promotion will be done by Liaison 
Librarians. But the advantage is that academic staff become involved, collaboratively, in the enterprise of web resource description for the institution via the Library, and also that the quality of the selected resources is likely to be high. This approach most closely mimics the book suggestion forms with which we have long worked (with the publisher's catalogue being the source of information, and the form being the trigger), and makes for a genuinely demanddriven system.

\section{Conclusion}

Virtual learning environments are changing the way teaching and learning are delivered - and have the potential to change even the activities which comprise the learning experience of students on some courses. While they are still largely associated with solving problems of scale through the packaging of course materials for asynchronous delivery, they will become more and more widespread even in 'traditional' on-campus lecture-based courses, because they provide efficiencies in the administration of the process.

Libraries must ensure that they remain part of the process as virtual learning takes hold. They must explain their role in the information management chain more clearly to their academic colleagues, and this process will involve a degree of justification of the practices of librarianship from first principles. Virtual learning environments must also be virtuous learning environments, practising resource efficiency through the incorporation of learning resources in institution-wide library resource description systems - which now interoperate globally for the benefit of whole subject domains. Reclaiming their role in the institution is an urgent requirement upon librarians. It involves full and active liaison and the inclusion of librarians alongside course developers. As the relative expenditure of professional library effort required for managing print collections reduces, we must ensure that our response is not simply to redirect that effort into computer programming and software development, important though that is. Significant redirection, particularly for our more traditional university libraries, must be towards liaison and collaboration with those engaged in the core mission of our universities.

\footnotetext{
1 http://toomol.bangor.ac.uk/ll/index.html

http://www.webct.com/

http://www.blackboard.com/

http://www.wbtsystems.com/

http://www.hull.ac.uk/merlin/inframe.html

http://www.longman.net/COSE/index.html

Mason, R. 'Models of online courses' ALN Magazine 2(2) October 1998

[http://www.aln.org/alnweb/magazine/vol2_issue2/Masonfinal.htm]

8 See http://www.intrallect.com

9 http://www.imsproject.org

$10 \mathrm{http}: / / \mathrm{www}$.adlnet.org

11 http://intranet.usyd.edu.au/tour/myuni.html

$12 \mathrm{http}: / / \mathrm{www} . c a m p u s p i p e l i n e . c o m /$

13 JISC 'Managed Learning Environments: a workshop run by JISC Assist, 29 February and 7 March 2000: Final Report' [http://www.jisc.ac.uk:8080/pub00/mle/final_rep.html]

14 http://www.heron.ac.uk

15 Pan, R. 'Digitisation projects at the University of Durham - E-reserves, exam papers and more...' (JANET User Group for Libraries Conference: Digitisation in Practice: Reallife stories...., 9 January 2001, Open University Conference Centre, London)

16 See his frequent use of the term to denote resources which are paid for, usually by means of electronic licence subscriptions, in the archives of the email conference he maintains on scholarly publishing, september98-forum (http://listserver.sigmaxi.org/archives/september98-forum.html)
} 
17 Burnett, P and Seuring, C. 'Organising access to free Internet resources: an overview of selection and management issues in large academic and national libraries with a view to defining a policy at Oxford University', Program 35 (1) January 2001

18 http://www.oclc.org/corc/ 